\title{
THE
}

$1-13-2015$

\section{Collagen Gel Formation in the Presence of a Carbon Nanobrush}

\author{
George W. Dombi \\ University of Rhode Island, gdombi@uri.edu \\ Kaushalkumar Purohit \\ University of Rhode Island \\ Lenore M. Martin \\ University of Rhode Island, martin@uri.edu \\ Sze C. Yang \\ University of Rhode Island, syang@uri.edu
}

Follow this and additional works at: https://digitalcommons.uri.edu/chm_facpubs

The University of Rhode Island Faculty have made this article openly available.

Please let us know how Open Access to this research benefits you.

This is a pre-publication author manuscript of the final, published article.

Terms of Use

This article is made available under the terms and conditions applicable towards Open Access

Policy Articles, as set forth in our Terms of Use.

\section{Citation/Publisher Attribution}

Dombi, G.W., Purohit, K., Martin, L.M. et al. J Mater Sci: Mater Med (2015) 26: 30. https://doi.org/10.1007/ s10856-014-5356-4

Available at: http://dx.doi.org/10.1007/s10856-014-5356-4

This Article is brought to you for free and open access by the Chemistry at DigitalCommons@URI. It has been accepted for inclusion in Chemistry Faculty Publications by an authorized administrator of DigitalCommons@URI. For more information, please contact digitalcommons-group@uri.edu. 


\section{Collagen Gel Formation in the Presence of a Carbon NanoBrush}

George W. Dombi ${ }^{* 1}$, Kaushalkumar Purohit ${ }^{1}$, Lenore M. Martin ${ }^{2}$, Sze C. Yang ${ }^{1}$

${ }^{1}$ Department of Chemistry,

${ }^{2}$ Department of Cell and Molecular Biology,

University of Rhode Island

Kingston, RI 02881, USA

* Corresponding author George W. Dombi, PhD

E-mail address: Gdombi@Chm.uri.edu

September 10, 2012 


\begin{abstract}
Type I, bovine skin collagen was allowed to gel in the presence of various concentrations of a carbon nanotube material covered with a polystyrene/polyaniline copolymer, called a carbon nanobrush, CNB. The rate of collagen gelation was enhanced by the presence of the CNB in a dose dependent manner. The extent of collagen gelation was due to the concentration of collagen and not the amount of CNB. Collagen D-periodicity, and average fibril diameter were unchanged by the CNB material as seen in transmission electron micrographs. Gel tensile strength was reduced by the presence of the the CNB in a dose related manner. The collagen-CNB mixture may have a role in the repair and reconstruction of wounds or degenerated connective tissue.
\end{abstract}

\title{
Introduction
}

Type I collagen is the most abundant protein in the human body as well as in other vertebrates. Collagen is the major structural protein of skin, tendon, ligament, bone and artery walls. Native collagen is highly cross-linked in the tissues where it resides as part of the extra-cellular matrix. Fibroblasts embedded in the extra-cellular matrix synthesize and export collagen as a composite of 3 alpha subunits, that form a single, linear collagen monomer with a triple, left handed helical twist that is about $300 \mathrm{~nm}$ long and $1.5 \mathrm{~nm}$ wide. Multiple collagen monomers, self-associate in the extracellular matrix to form longer and thicker structures called fibrils in skin, which in-turn can combine in tendons to form larger structures called fibers. Collagen structures resemble rope because of the alternating twist in the helical orientation, this provides strength and decreases unraveling under extension, [1]. 
Type I collagen, in skin, forms fibrils in the presence of other extra-cellular matrix proteins especially proteoglycans which are comprised of a protein core surround by long chains of polysaccharides. Although collagen, in vitro, self-assembles without the presence of these proteoglycans, it is thought that the presence of those large molecular weight proteoglycan molecules limit the in vivo size and orientation of collagen fibrils so that longer, wider fibers are not formed, [2].

Collagen monomers can be isolated from a number of tissues using pepsin treatment to breakup the cross-links. Isolated collagen monomers can re-assemble in vitro to form fibrils that resemble those in living tissue, with a characteristic $67 \mathrm{~nm}$ periodic structure called a D-period. [3,4]

There is much interest in carbon nanotubes as a reinforcement additive for tissue engineering materials such as collagen gels, and cartilagenous simulants, [5-9]. In the present work, results are presented showing the in-vitro fibril formation of pepsin treated collagen in the presence of carbon nanotubes coated with polystyrene/polyanaline side chains, which resemble, somewhat, proteoglycan macromolecules, [10].

\section{Material and Methods}

Collagen monomer solution, PureCol brand collagen, (type I, bovine skin, collagen solution, 3.0 $\mathrm{mg} / \mathrm{ml}$, isolated by limited pepsin digestion) was purchased from Advanced BioMatrix, Inc (San Diego, CA). Pepsin digest partially removes the telopeptides of native collagen, which allows the collagen cross-linkages to be broken and isolated from the native tissue.

Collagen fibril formation buffer, All buffer chemicals were reagent grade or better. 2x PBS, gelation buffer contained $60 \mathrm{mM}$ NaHPO4, $400 \mathrm{mM} \mathrm{NaCl}, 60 \mathrm{mM}$ TES, with $\mathrm{pH}$ adjusted to either 7.0 or 8.0 using $3.0 \mathrm{M} \mathrm{NaOH}$.

Carbon Nanobrush composite, High purity, multiple wall carbon nanotubes (CNT) were purchased from NanoLab, Inc. (Waltham, Ma). About $14 \mathrm{mg}$ of carbon nanotube material was 
sonicated in distilled water for 20 minutes to reduce the number of CNT self-attachments producing a CNT suspension. The carbon nanobrush was made by electrostatically attaching conductive polymer bristles to the central carbon nanotube core forming a conductive carbon nanobrush complex. The conductive polymer bristles were formed using template guided synthesis made by the association of polystyrene sulfonic acid and polyaniline to form a double stranded polymer. To attach this conductive polymer to the carbon nanotubes, an aqueous solution of $56 \mathrm{mg}$ of polystyrene sulfonic acid and polyaniline was added to the CNT to give a total volume of $40 \mathrm{ml}$. This solution was sonicated for an additional 20 minutes at room temperature to produce the conductive nanobrush $(\mathrm{CNB})$ in a homogeneously dispersed solution, which has a carbon nanotube at the core surrounded by helical bristles of polystyrene/polyanaline. The $40 \mathrm{ml}$ volume was dialyzed against 50 volumes of de-ionized water, over night, at room temperature to separated the excess, unattached bristles and any broken carbon nanotubes, [11]. The resulting carbon nanobrush material contains about $20 \% \mathrm{CNT}$ and $80 \%$ plystyrene/polyanaline by mass. A working solution was made by diluting the dialysate to a concentration of $8.0 \mathrm{mg}$ of $\mathrm{CNB}$ in $50 \mathrm{ml}$ of de-ionized water.

Collagen fibril formation, Collagen gelation solutions were prepared one of two ways. First, by mixing $1 \mathrm{~mL}$ of collagen monomer stock solution, $3 \mathrm{mg} / \mathrm{mL}$, with $0.9 \mathrm{ml}$ of 2x PBS buffer, $\mathrm{pH} 7.0$ and 0-100 uL of CNB stock solution plus sufficient de-ionized water to make a $2.0 \mathrm{~mL}$ volume of working solution, $0.15 \% \mathrm{w} / \mathrm{v}$ collagen. Second, by mixing $1 \mathrm{~mL}$ of $2 \mathrm{x}$ PBS buffer, $\mathrm{pH} 8.0$, with $0.9 \mathrm{~mL}$ of collagen monomer stock solution and $0-50 \mathrm{uL}$ of CNB solution plus sufficient de-ionized water to make a $2.0 \mathrm{~mL}$ volume working solution, $0.135 \% \mathrm{w} / \mathrm{v}$ collagen. Gelation solutions were manually scanned every 6 minutes, in quartz cuvettes, at $354 \mathrm{~nm}$ using a Genesys-10 UV scanning spectrophotometer zeroed against the fibril formation buffer with no CNB. Temperature was regulated using a dry well electric heating block where the cuvettes incubated between UV readings. This 
method of heating the collagen solutions had a temperature variation of $\pm 2{ }^{\circ} \mathrm{C}$. Fibril formation kinetics were assessed at three temperature ranges $30-32,33-35,38-40{ }^{\circ} \mathrm{C}$, using collagen solutions containing 50 ul of CNB stock solution.

Pseudo-kinetic parameters, $\mathrm{OD}(\max )$ and $\mathrm{T}^{1} / 2$ were determined with a 4 parameter, logistic regression fitting equation by plotting $\mathrm{OD}(354 \mathrm{~nm})$ as a function of time and iterating to a minimal sum of squared errors using the non-linear Solver routine in a spreadsheet program.

$$
\mathrm{OD}(354 \mathrm{~nm})=\frac{(\mathrm{OD}(\text { init })-\mathrm{OD}(\max )}{\left(1+\left(\text { time } / \mathrm{T}^{1} / 2\right)^{\wedge} \text { slope }\right)}+\mathrm{OD}(\max )
$$

Where $\mathrm{OD}$ (init) is taken from the first reading of the sample.

$\mathrm{T} 1 / 2$ was initially estimated as time to half the full OD from the raw data.

Slope was initially estimated as 5 OD units/min.

$\mathrm{OD}$ (max) is initially estimated at $3.0 \mathrm{OD}$ units.

$\triangle \mathrm{OD}$ was equal to $\mathrm{OD}(\max )-\mathrm{OD}$ (init).

Transmission electron microscopy, Samples of collagen gel were examined by a Joel Corporation, JEM 2100 TEM operating at 0.2 Mvolts. A 1\% wt/v sodium phosphotungstate solution was used as a heavy metal counter stain to highlight the collagen fibril D-period bands, which were measured as well as the fibril widths. Collagen gels formed with $1 \mathrm{~mL}$ of $2 \mathrm{x}$ PBS buffer, $\mathrm{pH} 8.0$, and $0.9 \mathrm{~mL}$ of collagen monomer stock solution were allowed to set overnight with 0 and $50 \mathrm{uL}$ of CNB. Measurements of the D period and fibril widths were made manually from the photographic images using the magnification scale printed on the image, which was $200 \mathrm{~nm}$ in length.

Tensile strength measurements, Samples of collagen gel were examined by a Bohlin Instruments Model CVO rotational rheometer, operated at $23.5 \pm 0.5^{\circ} \mathrm{C}$, with a set oscillation frequency of $1.0 \mathrm{hz}$. Collagen solutions were allowed to gel directly in the rheometer sample chamber at $35^{\circ} \mathrm{C}$ by mixing 1 part 10x PBS buffer with 8 parts PureCol collagen plus enough $0.5 \mathrm{M} \mathrm{NaOH}$ to bring to $\mathrm{pH} 8.0$ and 0 , 
50 or $100 \mathrm{uL}$ of CNB depending on the run. Two different lots of collagen were utilized to form the gels. Lot 4060 was the same lot used in the kinetic and TEM examinations. Lot 6006 was a newer lot used to provide some measure of collagen monomer solution shelf-life stability. A modified Young's modulus was calculated as the slope of the shear stress (pa) plotted as a function of the strain. The Young's modulus was plotted as a function of the CNB addition volume in uL.

\section{Results}

Three sets of optical density experiments were conducted utilizing the CNB material. The use of $354 \mathrm{~nm}$ as the wavelength to monitor collagen gelation was a compromise between the strong absorbance of the $\mathrm{CNB}$, $\max 313 \mathrm{~nm}$, and limitation of the spectrophotometer maximal optical density reading at 3.0 absorbance units.

Collagen fibril formation at pH 7.0 with $0,10,25,50$ and $100 \mathrm{uL}$ of the CNB material was found to accelerate the rate and extent of collagen gel formation in a dose dependent manner. At $\mathrm{pH}$ 7.0 the collagen-only sample did not form a solid gel even after 200 min, see Figure 1a. In previous gelation experiments that utilized collagen with the telopetides intact, these conditions would have resulted in gel formation in the collagen-only controls, $[3,4]$.

Collagen fibril formation at $\mathrm{pH} 8.0$, with $0,5,15,30$ and $50 \mathrm{uL}$ of the CNB material was also found to accelerate the formation of a collagen gel in a dose dependent manner. At $\mathrm{pH} 8.0$ the collagen-only sample was able to form a solid gel with a $\mathrm{T}^{1} / 2$ of $90.15 \mathrm{~min}$, see Figure $1 \mathrm{~b}$. Table 1 , shows the comparison of these gelation experiments. The extent of collagen fibril formation, $\Delta \mathrm{OD}$, is dependent on the initial concentration of collagen and not on the initial amount of CNB material. This can be seen in the consistent $\Delta \mathrm{OD}$ value reached at the end of each run. The mean $\Delta \mathrm{OD}$ of the 1.5 $\mathrm{mg} / \mathrm{mL}$ collagen samples were significantly larger, $(0.367 \mathrm{OD}, \mathrm{p}=0.004, \mathrm{df}=8)$ than the corresponding 
mean of the $1.35 \mathrm{mg} / \mathrm{mL}$ samples, which was expected since there is more collagen in the earlier samples. Speed of the fibril formation was found to depend on both $\mathrm{pH}$ and the initial amount of CNB material. In general as the amount of CNB material increased the rate of fibrilogenesis increased.

Collagen fibril formation with bristle polymers only. Figure 2 shows the effect of adding only the helical bristles of polystyrene/polyanaline, $(0,25,50$ and $100, \mathrm{uL})$ to the collagen monomer solution. This experiment was conducted at pH 7.0 PBS and as in Figure 1a above, the collagen-only sample failed to gel. The positive control of the $50 \mathrm{ul}$ of CNB sample was the only one to gel completely, $\left(\Delta \mathrm{OD}=2.229\right.$ and $\left.\mathrm{T}^{1} / 2=50.69 \mathrm{~min}\right)$, both values are comparable to the $50 \mathrm{uL} \mathrm{CNB}$ shown in above, Table 1. The polystyrene/polyanaline bristle samples showed a concentration dependent inhibition of collagen gelation, with a 50\% inhibition dose of $40 \mathrm{uL}$, Table 2.

Effects of temperature on collagen fibril formation. Figure 3 shows that collagen gelation occurred more quickly at higher temperatures. The slopes of the temperature vs CNB graphs were negative and had a steeper slope as CNB concentration increased and set temperature increase. This means that the effect of the CNB to organize the collagen monomers to self-assemble was greatest at lower temperature and high CNB concentration. These lines to not include a collagen-only sample because there was no collagen fibril formation at temperatures below $38-40{ }^{\circ} \mathrm{C}$.

Effects of CNB on collagen fibril TEM structure. Figure 4 shows the images of collagen fibrils formed under two conditions. Figure 4, left, shows the collagen-only control and Figure 4, right, shows the collagen plus $50 \mathrm{uL}$ of CNB. The scale bar under the left-hand image is $200 \mathrm{~nm}$. Measurement of the D-period, which is the repeat distance between series of bands, is usually reported at $67 \mathrm{~nm}$. This demonstrated that there was no statistical difference between the D periods of the collagen fibrils formed in the presence of $50 \mathrm{uL}$ of CNB samples, $65.9 \pm 2.4 \mathrm{~nm}$ (mean \pm std. dev) compared to the collagen-only control samples, $65.3 \pm 8.8 \mathrm{~nm}$. Also there was no statistical difference between the 
mean fibril widths; collagen plus $50 \mathrm{uL}$ of CNB samples measured $79.8 \pm 17.9 \mathrm{~nm}$ (mean \pm std. dev, $\mathrm{n}=20$ ) compared to the control samples, $84.8 \pm 46.0 \mathrm{~nm}, \mathrm{n}=30$.

Tensile strength changes as a result of $C N B$ addition. Figure 5 shows that the Young's modulus was reduced in a dose dependent manner as a function of CNB addition. The average of 6 measurements at $0 \mathrm{uL} \mathrm{CNB}$ indicates that the Young's Modulus was $122.8 \pm 9.8$ pascals. This was significantly different than the average of 3 measurements at $50 \mathrm{uL} \mathrm{CNB}$, Young's Modulus $96.6 \pm 2.1$, and 3 measurements at $100 \mathrm{uL}$, Young's Modulus 90.7 \pm 10.4 pascals, (ANOVA, $\mathrm{F}=16.6, \mathrm{p}<0.001$ ). The $50 \mathrm{uL} \mathrm{CNB}$ and $100 \mathrm{uL}$ CNB samples were not significantly different, (Tukey HSD, $\mathrm{p}=\mathrm{ns}$ ). The reduction in Young's modulus was contrary to the original expectation that the CNB material would stiffen the collagen gel.

\section{Discussion}

Collagen fibril formation in-vitro has been well studied for over 50 years, $[12,13]$. It has been found that when the collagen monomers are isolated from the parent tissue using mild, neutral salt extraction methods, the collagen has its non-helical terminal ends intact, $[3,13,14]$. When the collagen monomers are isolated using harsher, pepsin digestion methods, the collagen yield is higher but the cross-linkages sites at the non-helical, terminal ends are remove, $[15,16,17]$. Both neutral salt soluble and pepsin digest soluble collagen will form native-like fibrils in-vitro given the appropriate conditions of $\mathrm{pH}$, temperature and solution ionic strength. In our hands, conditions for gelation of neutral salt soluble monomers is $\mathrm{pH} 7$, and $20-23^{\circ} \mathrm{C}$ and conditions for gelation of pepsin solubilized monomers is pH 8.0 and $35-37^{\circ} \mathrm{C}$.

When solution turbidity is monitored, collagen fibril formation consists of a lag phase followed by a growth phase that ends in a plateau region, [18]. During the lag phase of the time course, fibril assembly proceeds by nucleation events that do not change solution turbidity. During the growth phase, 
lateral association of collagen monomers to the nuclei produce banded collagen fibrils and a rapid change in solution turbidity. The plateau phase is reached when all the monomers are incorporated into fibrils. The lateral aggregation during the growth phase is considered to be a hydrophobic, entropydriven process in which the net system increase in disorder is due to the release of associated water molecules, [19].

The collagen utilized in the current experiments was a pepsin solubilized material. This was reflected in the higher temperatures needed to promote gelation in the collagen-only samples. The presence of the carbon nanobrush material had a strong promotion effect even to lower temperatures of $30^{\circ} \mathrm{C}$. No experiments were conducted at $20-23{ }^{\circ} \mathrm{C}$, which is the temperature at which collagen isolated with the milder neutral-salt solution can for a gel.

Structurally, the carbon nanobrush resembles the proteoglycan molecule in so much as the carbon nanotube forms a rigid backbone like the protein core of the proteoglycan molecule and the polystyrene/polyanaline bristles of the CNB resemble the polyglycan side chains of the proteoglycan molecule. We speculate that the polystyrene/polyanaline side chains are able to interaction with collagen monomers and act like a surface template to help guide the monomers to align themselves to form fibrils without having to form independent collagen-only nucleation centers, [20]

The most probable reason that the polystyrene/polyanaline side chains alone did not promote collagen gelation was because the bristle material was able to coat the collagen monomers and prevent other monomers from interacting. This behavior is like that of other amphoteric molecules binding to collagen. Both the surfactant, sodium dodecyl sulfate and the soluble salt steroid, dexamethasone disodium phosphate, inhibited collagen monomer interactions at high concentrations where nonspecific hydrophobic interactions occurred, acting to mask the collagen attachment sites, [4, 21]. It was seen by the TEM pictures that the native D-period was maintained in both the collagenonly samples and the test collagen sample containing $50 \mathrm{uL}$ of CNB. This was anticipated that if the 
fibrils were formed they would be native-like since similar results where seen in collagen gels formed in the presence of surfactants and soluble steroids, which act like a rigid surfactant, [4, 21]. It is probably that the carbon nanobrush material forms a core around which the collagen monomers associate, then additional collagen monomers add next to the first layer in their usual staggered orientations which produce the D-period in the native collagen material.

The effects of temperature of collagen gelation show a Q10-like response so that the gelation events occur faster at higher temperatures and slow if at all, at lower temperatures. The probable reason that the CNB material allowed the pepsin-treated collagen to form fibrils at the lower temperature is because without the telopeptide ends to help guide nucleation events, the collagen monomers simply associated with the CNB material.

The reduction in tensile strength, due to the addition of $\mathrm{CNB}$ material is more complex to explain. Since one might expect that the CNB would act like a reinforcement, and stiffening bar in the collagen gel. It is generally thought that collagen gel strength is a result of collagen concentration and the extent of cross-linkages between the collagen fibrils, but also gel strength can be the result of the extent to which the individual fibrils are intertwined. If the fibrils were all parallel, then strength of the gel would show little viscoelastic effects as strength would simply be a measure of the resistance to sliding past each other until the individual fibril would break. But the fibrils in a gel do randomly fold over each other, which does produce a larger viscoelastic effect. The fibrils must first reorient along the direction of the stretch and then slide past each other and then finally break.

In the present case, where the collagen-only controls are stronger than the collagen with CNB material, it could mean that first, the collagen-only fibrils are bigger, forming more cross-linkages with their neighbors, or second, the fibrils are more intertwined. Tensile tests alone can not distinguish the proportions of these two effects since strength is a combination of the two. In this experiment, we did 
not do any scanning electron microscopy, therefore we didn't measure the orientation or the extend of the s-shaped turns in individual fibrils. The TEM study shows that the collagen-only fibrils are nonsignificantly larger than the $50 \mathrm{uL} \mathrm{CNB}$ containing gels.

Our future experiments will examine the orientation and the extend of s-shaped turns in the individual fibrils as a function of CNB concentration. Also, we will explore the upper levels of collagen fibril formation (gelation) tolerance to CNB concentration. It is assumed that at some high enough level, CNB will inhibit collagen fibril formation as the individual collagen monomers will be blocked from interacting because of their association with the CNB material. Finally, we plan to use these collagen gels, made in the presence of the CNB material as a fibroblasts culture media to determine the extent of collagen gel contraction induced by normal fibroblast activity.

The goal of this work is to produce a collagen hydrogel material that is fibroblast compatible and has a tensile strength that can be controlled by the amount of CNB added. Different types of tissue repair would require different types of collagen gel tensile strength.

\section{Acknowledgements}

The authors wish to thank Mr. Richard White for his use of the Jasco TEM instrument and to thank Mr. David Bagley, of Advanced BioMatrix for his rheometric testing of the collagen gel samples. 


\section{References}

[1] L. Bozec, G. van der Heijden and M. Horton, Collagen Fibrils: Nanoscale Ropes. Biophys J, 92 (2007), 70-75.

[2] G.C. Wood, The Formation of Fibrils from Collagen Soutions, \#3 Effect of Chondroitin Sulphate and Some Other Naturally Occurring Polyanions on the Rate of Formation. Biochem. J, 75 (1960), 606-612.

[3] B.R. Williams, R.A. Gelman, D.C. Poppke and K.A. Piez, Collagen Fibril Formation - Optimal In Vitro Conditions and Preliminary Kinetic Results. J. Biol. Chem, 253 (1978), 6578-6585.

[4] G.W. Dombi and H.B. Halsall, Collagen Fibril Formation in the Presence of Sodium Dodecyl Sulphate. Biochem. J, 228 (1985), 551-556.

[5] R.A. MacDonald, B.F. Laurenzi, G. Viswanatha, P.M. Ajayan and J.P. Stegemann, CollagenCarbon Nanotube Composite Materials as Scaffold in Tissue Engineering. J. Biomed. Mater. Res, Part A, 74 (2005), 489-496.

[6] S. Bhattacharyya, J.P. Salvetat and M.L. Saboungi, Reinforcement of Semicrystalline Polymers with Collagen-Modified Single Walled Carbon Nanotubes. Appl. Phys. Lett, 88, (2006), 233119.

[7] L.P. Zanello, B. Shao, H. Hu and R.C. Haddon, Bone Cell Proliferation on Carbon Nanotubes. Nano Lett, 5 (2006), 562-567.

[8] I. Sridharan, T. Kim and R. Wang, Adapting Collagen/CNT Matrix in Directing hESC Differentiation. Biochem, Biophys, Res. Com, 381 (2009), 508-512. 
[9] W. Tan, J. Twomey, D.Guo, K Madhavan and M. Li, Evaluation of Nanostructural, Mechanical and Biological Properties of Collagen-Nanotube Composites. IEEE Transaction on Nanobioscience, 9 (2010), 111-120.

[10] J.H. Highberger, J. Gross and F.O. Schmitt, The Interaction of Mucoprotein with Soluble Collagen; an electron Microscope Study. Proc National Acad Sci, 37 (1951), 286-291.

[11] K. Purohit, M. Mirville, S.C. Yang, A. Shukla and V. B. Chalivendra, Conductive Nano-Brush Synthesized by Physical Grafting of Conducting Polymers on Carbon Nanotube. in: Hierarchical Materials and Composites. (Materials Research Society Symposium Proceedings Vol. 1304) 2011.

[12] J. Gross, J.H. Highberger, and F.O. Schmitt, Extraction of Collagen From Connective Tissue by Neutral Salt Solutions. Proc National Acad Sci, 41 (1955), 1-7.

[13] G. Chandrakasan, D.A. Torchia and K.A. Piez, Preparation of Intact Monomeric Collagen from Rat Tail Tendon and skin and the Structure of the Nonhelical Ends in Solution. J. Biol. Chem, 251 (1976), 6062-6067

[14] R.A. Gelman, B.R. Williams and K.A. Piez, Structure and Assembly of the Native Collagen Fibril. J. Biol. Chem, 254 (1979) 180-186.

[15] J.McK. Snowden and D.A. Swann, The Formation and Thermal Stability of In Vitro Assembled Fibrils from Acid-soluble and Pepsin-treated collagens. Biochem et Biophys Acta, 580 (1979) 372381.

[16] M.J. Capaldi and J.A. Chapman, The C-terminal Extrahelical Peptide of Type I Collagen and its Role in Fibrillogenesis In Vitro. Biopolymers, 21 (1982) 2291-2313. 
[17] M. Miyahara, K. Hayashi, J. Berger, K. Tanzawa, F.K. Njieha, R.L. Trelstad and D.J. Prockop, Formation of collagen fibrils by enzymic cleavage of precursors of type I collagen in vitro. $\mathbf{J}$ Biol Chem, 259, (1984), 9891-9898.

[18] G.C. Wood and M.K. Keech, Formation of Fibrils from Collagen Solutions, \#1 The Effect of Experimental Conditions: Kinetic and Electron-Microscope Studies. Biochem. J, 75 (1960), 588-598.

[19] A. Cooper, Thermodynamic Studies of the Assembly In Vitro of Native Collagen Fibrils.

Biochem. J, 118 (1970), 355-365.

[20] S. Linse, C. Cabaleiro-Lago, W. Xue, I. Lynch, S. Lindman, E. Thulin, S.E. Raford and K.A. Dawson, Nucleation of Protein Fibrillation by Nanoparticles. Proc National Acad Sci, 104 (2007), $8691-8696$.

[21] G.W. Dombi and H.B. Halsall, Collagen Fibril Formation in the Presence of Dexamethasone Disodium Phosphate. Connective Tissue Research, 15 (1986), 257-268. 